\title{
TUBERCULOMA PRESENTING AS ATYPICAL ECLAMPSIA- A CASE REPORT
}

\author{
Shashi Prateek1, Geetika Nain², Lalita Yadav³, Abha4, Eshna Gupta ${ }^{5}$
}

1 Professor and HOD, Department of Obstetrics and Gynaecology, Subharti Medical College, Meerut, Uttar Pradesh.

2Junior Resident, Department of Obstetrics and Gynaecology, Subharti Medical College, Meerut, Uttar Pradesh. ${ }_{3}^{3}$ Assistant Professor, Department of Obstetrics and Gynaecology, Subharti Medical College, Meerut, Uttar Pradesh. ${ }^{4}$ Assistant Professor, Department of Obstetrics and Gynaecology, Subharti Medical College, Meerut, Uttar Pradesh. 5Junior Resident, Department of Obstetrics and Gynaecology, Subharti Medical College, Meerut, Uttar Pradesh.

HOW TO CITE THIS ARTICLE: Prateek S, Nain G, Yadav L, et al. Tuberculoma presenting as atypical eclampsia- a case report. J. Evolution Med. Dent. Sci. 2018;7(13):1677-1678, DOI: 10.14260/jemds/2018/378

\section{PRESENTATION OF CASE}

Eclampsia is defined as development of tonic-clonic convulsions or coma in a woman with preeclampsia, which cannot be contributed to any other cause. Occurrence of eclampsia before 20 weeks of pregnancy and after 48 hours of delivery in the absence of typical signs of hypertension and/or proteinuria is termed as atypical eclampsia. Atypical or non-classic eclampsia will have some symptoms of eclampsia, but without the usual proteinuria or hypertension. All patients with atypical onset should undergo neurological evaluation to rule out neurologic causes of seizures. Cerebral tuberculosis is a rare and serious form of disease secondary to haematogenous spread of Mycobacterium tuberculosis. Here, we present a case of cerebral tuberculoma with seizures in late pregnancy mimicking eclampsia.

\section{CLINICAL DIAGNOSIS}

A 22-year-old lady gravida one, unbooked case came to emergency of Subharti Medical College with history of 7 months of pregnancy and chief complaint of 2 episodes of seizures.

Apparently her antenatal period was uneventful till she developed seizures, which were tonic and clonic in nature, associated with tongue bite and frothing from mouth.

There was no history suggestive of urine and stool incontinence or any other seizure disorder. Patient's B.P on admission was $140 / 90 \mathrm{~mm}$ of $\mathrm{Hg}$ and proteinuria was $1+$. She was diagnosed as a case of Eclampsia and magnesium sulphate therapy was started.

Patient's caesarean section was done due to non-progress of labour and she delivered a male baby of $1.3 \mathrm{~kg}$. Baby was admitted in nursery due to prematurity. Patient was given magnesium sulphate regime for 24 hours post-delivery. Patient had repeat episode of seizure on postnatal day 2. Her MRI brain (plain and contrast) was done, which revealed multiple discrete and conglomerated appearing ring enhancing lesions with surrounding white matter oedema and swollen overlying gyri involving right parietal region associated leptomeningeal enhancement suggestive of tubercular pathology.

Patient was started with antitubercular and antiepileptic drugs. She responded to treatment well and was discharged under satisfactory condition.

'Financial or Other Competing Interest': None.

Submission 31-01-2018, Peer Review 09-03-2018,

Acceptance 16-03-2018, Published 26-03-2018.

Corresponding Author:

Dr. Geetika Nain,

136/5A, Mission Compound Dwarikapuri,

Muzaffarnagar-251001, Uttar Pradesh.

E-mail: geetikanain90@gmail.com

DOI: $10.14260 /$ jemds $/ 2018 / 378$

\section{(c) (i) $(9)$}

\section{DISCUSSION OF MANAGEMENT}

Eclampsia classically presents as hypertension and proteinuria with seizures and/or coma after 20 weeks of gestation upto 48 hours of delivery, occurrence of eclampsia before 20 weeks of pregnancy and after 48 hours of delivery in the absence of typical signs of hypertension and/or proteinuria is termed as atypical eclampsia.[1] Atypical or non-classic eclampsia will have some symptoms of eclampsia, but without the usual proteinuria or hypertension.[1] All patients with atypical onset are therefore advised to undergo neurological evaluation to rule out neurologic causes of seizures.

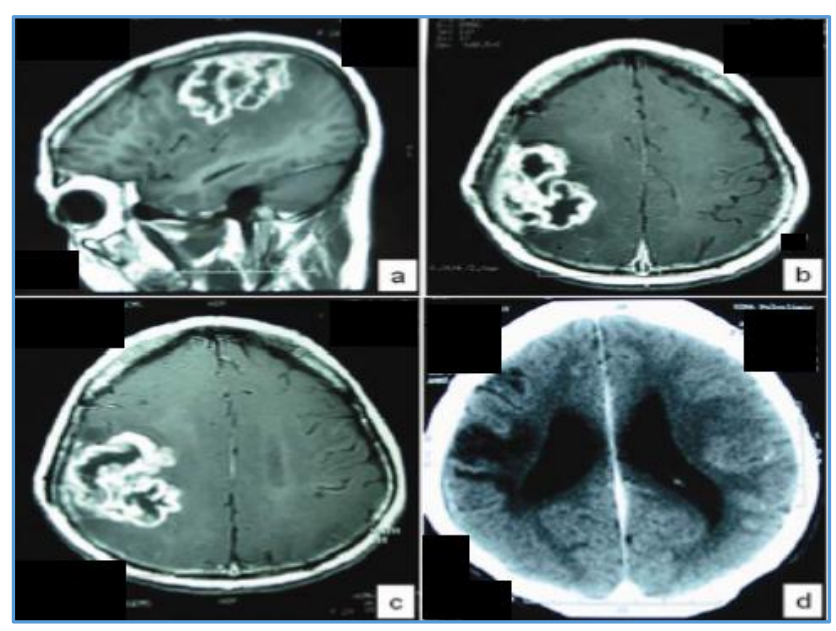

Figure 1. (A-C) Axial MRI showing Dural Based Contrast Enchanching Lesion, Contrast CT Scan after One Year (D)

Previously undiagnosed space occupying lesions form an important differential diagnosis for atypical eclampsia. Tuberculosis is the second greatest killer after HIV/ AIDS due to a single infectious agent and continues to be an important public health problem in developing countries. About a third of the world's population has latent tuberculosis. Although, all age groups are at risk, it commonly affects young adults. Globally in 2013, 3.3 million women fell ill with tuberculosis, $70 \%$ of these women were from African and Southeast Asian regions. ${ }^{[2]}$ The incidence of tuberculosis in pregnancy ranges between $1 \%-2 \%$. Tuberculosis among mothers is associated with a six-fold increase in perinatal mortality and a two-fold rise in prematurity and low birth weight. When associated with HIV, it increases the risk of maternal and infant mortality by $300 \%$.[2]

Dissemination of the disease is common among immunocompromised patients. When dissemination occurs, any organ may be affected. In CNS, the infection is classified as intracranial and spinal.[3] Tuberculosis of the brain may be a part of a systemic disease or occur in isolation usually as a 
seeding from a silent pulmonary lesion. It may involve the meninges or parenchyma or both. The intracranial tuberculosis usually presents as meningitis and less commonly as tuberculoma. ${ }^{[4]}$ A tuberculoma forms when a tubercle in the brain parenchyma enlarges without rupturing into the subarachanoid space. [5]

Seizures are one of the most common symptoms occurring in upto $85 \%$ of cases along with symptoms related to elevated intracranial pressure such as headache, papilloedema and lethargy as in the present case.[6] Pandole A et al reported a similar scenario where the patient presented with tonic-clonic seizures near term and had two intracranial tuberculomas which was operated upon soon after delivery.[7] Symptoms of focal mass lesion like weakness, hemiparesis and ataxia occur in $70 \%$ of patients. Nabulsi et al reported a case of an antenatal woman from Somalia with fulminant disseminated disease who presented with tubercular meningitis and later succumbed to the disease despite initiation of therapy.[8]

The diagnosis of tuberculoma during pregnancy is difficult, because often the eclampsia becomes the presumptive diagnosis in any convulsive pregnant woman. However, a small percentage of them could be normotensive and non-proteinuric. Such patients should be worked up for neurological causes of seizures.

The standard anti-tubercular regimen has two phases, an intensive phase and a continuation phase. In the intensive phase, the patient will receive 4 - 5 drugs lasting for 2 - 3 months in order to kill the fast multiplying bacilli. This is then followed by a continuation phase, where the patient receives 2 - 3 drugs lasting for 4 - 5 months, during which the remaining bacilli are killed so as to prevent a relapse. Some experts advise to prolong this continuation phase to $9-12$ months in cerebral tuberculosis, because of the associated morbidity. All pregnant and lactating women should be advised to take the full course, as antitubercular drugs are safe during pregnancy and lactation. Streptomycin is avoided in pregnancy, as it is ototoxic to the foetus. ${ }^{[9,10]}$

\section{FINAL DIAGNOSIS}

As atypical pre-eclampsia and eclampsia are very vague entities, it is better to keep other differential diagnoses like a space occupying lesion in mind. In patients coming from areas with a high incidence of tuberculosis, a cerebral tuberculoma should be thought of even in the absence of prior history or pulmonary involvement.

\section{REFERENCES}

[1] Stella CL, Sibai BM. Preeclampsia: diagnosis and management of the atypical presentation. J Matern Fetal Neonatal Med 2006;19(7):381-6.

[2] WHO factsheet $N^{*} 104$. Revised March 2015.

[3] Cherian A, Thomas SV. Central nervous system tuberculosis. African Health Sciences 2011;11(1):11627.

[4] Frosch MP, Anthony DC, De Girolami U. The central nervous system. In: Kumar V, Abbas AK. eds. Pathologic basis of the disease. $8^{\text {th }}$ edn. Elsevier Saunders 2010: p. 1301.

[5] Rock RB, Olin M, Baker CA, et al. Central nervous system tuberculosis: pathogenesis and clinical aspects. Clinical Microbiology Reviews 2008;21(2):243-61.

[6] Muin DA, Wagner K, Burian R, et al. Brainstem tuberculoma in pregnancy. Article ID 179483, Case Reports in Obstetrics and Gynecology 2015;2015: p. 6 http://dx.doi.org/10.1155/2015/179483

[7] Pandole A, Akolekar R, Vaidya N, et al. Tuberculoma in Pregnancy. Bombay Hospital Journal 2001;43(1):20001.

[8] Nabulsi BK, Kadi M, AlAbadi H, et al. Pregnant woman with fulminant disseminated TB to the omentum and placenta. Gynecol Obstet (Sunnyvale) 2014;4: p. 225.

[9] World health organization. Treatment of tuberculosis: guidelines $\quad 4$ th 2010 . WHO/HTM/TB/2009.420.

[10] Tripathi KD. Anti tubercular drugs. In: Tripathi KD. edr. Essentials of medical pharmacology. $7^{\text {th }}$ edn. Jaypee Publishing House 2013: pp. 765-79. 